\title{
A Narrative Literature Review of the Psychological Hindrances Affecting Return to Sport After Injuries
}

\author{
Ashley Sweeney*a, Stephanie M. Swanberg, \& Suran Kamel-ElSayed \\ ${ }^{a}$ Honors College, Oakland University, Rochester, MI \\ ${ }^{b}$ Michigan School of Psychology, Farmington Hills, MI \\ 'Department of Foundational Medical Studies, Oakland University, Rochester, MI \\ https:// doi.org/10.33697/ajur.2021.045 \\ Student: asweeney@oakland.edu*,ashsweeney25@gmail.com \\ Mentors: sswanberg@msp.edu, \& elsayed@oakland.edu
}

\begin{abstract}
After different sports injuries, athletes may experience various psychological emotions in response to such injuries, which could lead an athlete to feel stressed. These emotions include anger, fear, frustration, anxiety, and depression which may lead to lack of confidence in returning to their sport and/or fear of sustaining a new injury. This narrative review aims to determine the possible psychological hindrances present when an athlete is planning on returning to sport after injury to an anterior cruciate ligament (ACL) or after sustaining a concussion. The synthesized information for this review has been collected from researching the databases PubMed, SportDiscus, PsycInfo, and Google Scholar using search terms including "return to sport", "ACL injury", "concussion", and "psychology". Journal articles needed to be in English and published in the years 2009-2019; books and unpublished abstracts were excluded. A total of 42 studies were included and analyzed using deductive coding to organize and synthesize relevant articles into themes. The review summarizes the shared common and the different psychological hindrances that may be found in athletes after an ACL injury or concussion. Shared psychological characteristics for returning to sport following either an ACL injury or concussion included fear, self-esteem, control, anxiety, stress, recovery, and social support. Discovering the common and unique psychological barriers which may affect the injured athletes from returning to sport can help educate athletes' families, coaches, and healthcare professionals, as well as promote discussions for the future to help athletes feel more secure in their return to their respective sport.
\end{abstract}

\section{KEYWORDS}

ACL Injuries; Concussions; Sport Injuries; Athletes; Narrative Literature Review; Psychological Hindrances; Psychological Characteristics; Return to Sport; Psychology

\section{INTRODUCTION}

Sports have become an ever-dominant presence in our culture with many people choosing to play sports at the high school, collegiate, professional, or recreational level. Specifically, over 8 million high school students and nearly 500,000 college students participate in athletics as of the 2018-2019 year while 19.5\% of US adults participated in some form of daily exercise. ${ }^{1-3}$ Being involved in sports comes with the increased chance of injury, especially anterior cruciate ligament (ACL) injuries and sports related concussions.

ACL injuries are one of the most common sports related injuries in the United States with roughly 130,000 ACL reconstructions performed by doctors annually. ${ }^{4}$ Many athletes that sustain ACL injuries often undergo some type of rehabilitation, most commonly physical therapy, but sometimes this rehabilitation may come with a heightened risk of return to sport (RTS). Research suggests that $50 \%$ of patients that undergo ACL reconstruction may not be able to reach their previous level of sport, prior to injury. ${ }^{5,6}$ Although adequate rehabilitation and successful reconstruction are attainable in most athletes, RTS may not always be achievable since there are many other factors affecting RTS. They could be related to physical factors, (e.g., impairments an athlete may feel after sustaining their injury), contextual factors (e.g., social, and environmental pressures), and their own psychological hindrances they may be experiencing. ${ }^{7}$

Concussions pose another threat to the athlete, as this injury has many hidden symptoms. Since there are no outward physical impairments for concussions, it can be very difficult to predict how long it will take an athlete to recover. ${ }^{8}$ From $2010-2016$, there were over 280,000 hospital visits per year related to traumatic brain injuries, with about 45\% of those occurring from contact 
sports. ${ }^{9}$ While this is deemed as the "invisible" injury, the jolting of the brain when a concussion occurs can cause symptoms that may include headaches, anxiety, irritability, and memory impairments. ${ }^{10}$

Greater public concern around concussions has emerged as more health professionals and researchers gain a better understanding of how concussions affect the brain. ${ }^{11}$ Not only have concussions become a central focus for healthcare professionals, but also become aware of how concussions also impact parents and families of athletes who sustained these injuries. This awareness has prompted all 50 US states to pass laws to help safeguard athletes and support further research. ${ }^{12}$

This literature review provides an in-depth analysis of the psychological hindrances that affect RTS after sustaining an ACL injury or concussion. The focus of this review is on these two athletic injuries, as both injuries can have lengthy recovery times, complications, and similar impacts on the psychological health of athletes. Other sports injuries

were excluded by the authors to provide a narrow focus and allow for more concise data collection and synthesis.

\section{METHODS}

This literature review followed the matrix method of conducting literature reviews described by Goldman and Schmalz (2005). ${ }^{13}$ Inclusion criteria included English language journal articles published from (2009-2019) which summarized findings related to the psychological factors that may hinder athletes' return to sport after an ACL injury or concussion. Any age of athlete was also included. Exclusion criteria included injuries other than ACL or concussion. The databases of PubMed, SportDiscus, PsycInfo, and Google Scholar were searched using the search terms listed in the table below (Table 1).

\begin{tabular}{|c|l|}
\hline Database & \multicolumn{1}{|c|}{ Search Strategy } \\
\hline PubMed & $\begin{array}{l}\text { ((Anterior Cruciate Ligament OR ACL) AND (injury OR injuries OR tear OR tears OR reconstruction)) OR "Anterior } \\
\text { Cruciate Ligament Injuries"[Mesh] OR concussion* OR "Brain Concussion"[Mesh])) AND (fear* OR anxiety OR anxious OR } \\
\text { "Fear"[Mesh] OR "Anxiety"[Mesh]) AND ("return to sport" OR "return to play" OR "Return to Sport"[Mesh]) }\end{array}$ \\
\hline PsycINFO & $\begin{array}{l}\text { ((Anterior Cruciate Ligament OR ACL) AND (injury OR injuries OR tear OR tears OR reconstruction)) OR concussion*) } \\
\text { AND (fear* OR anxiety OR anxious) AND ("return to sport" OR "return to play") }\end{array}$ \\
\hline SportDISCUS & $\begin{array}{l}\text { ((Anterior Cruciate Ligament OR ACL) AND (injury OR injuries OR tear OR tears OR reconstruction) OR concussion*) AND } \\
\text { (fear* OR anxiety OR anxious) AND ("return to sport" OR "return to play") }\end{array}$ \\
\hline Google Scholar & (ACL injury* OR concussion*) AND (fear or anxiety) AND ("return to sport" OR “return to play") \\
\hline
\end{tabular}

Following the searches, the primary author reviewed and selected studies to include in the literature review based on the criteria. Each article was separated into either the ACL and concussion category, then divided into sub-categories or themes using the matrix method to organize and summarize the literature. The sub-categories were determined prior to data collection, followed by organizing the data through deductive coding. Once the categories were determined, each article was read a second time to determine the most relevant themes. For ACL injuries, the articles were grouped in the following categories: self-reported fear and fear of re-injury, and psychological factors hindering return to sport. For concussions, the articles were separated into the following categories: recovery patterns after sustaining a concussion; anxiety and social support post-concussion; depressive symptoms in concussed athletes and return to play after sustaining a concussion. No assessment of the methodological quality of the articles was conducted.

\section{RESULTS}

A total of 43 studies were included in this literature review. The following section summarizes the findings of these studies on ACL injuries and concussions, respectively.

\section{ACL Injuries}

\section{Self-Reported Fear and Fear of Re-injury}

The topic of fear and fear of re-injury was a common theme that emerged in this review. To determine an athlete's self-reported fear at the time of return to sport (RTS), Paterno et al. (2018) created a study in which they compared self-reported fear as well as the incidence of a second ACL injury within 24 months of that athlete sustaining their first injury ${ }^{14}$. Categories were created for individuals that had undergone ACL reconstruction (ACLR) ranging in ages from 10-25 years of age. In the Paterno et al. study, fear was measured using the shortened version of the Tampa Scale of Kinesiophobia (TSK) ${ }^{15}$ with the participants separated into two groups. In the TSK scale, those who scored a 17 or greater on the TSK-11 are categorized in the high fear group and those that scored 16 and lower were in the low fear group. ${ }^{15}$ Results of the study showed that those who reported a greater fear on the TSK-11 were up to four times more likely to show lower levels of activity once they had undergone ACLR. Comparatively, those who had returned to their normal states of performance prior to injury often reported higher levels of fear when demonstrating 
pivoting and cutting motions. This higher self-reported fear also led to those athletes having a higher risk of suffering a second ACL injury within the 24-month period in which the participants stayed in contact throughout the study. ${ }^{14}$

Tripp et al. (2011) conducted a similar study about confidence in RTS for athletes one year after having undergone ACLR. ${ }^{16}$ The TSK-11 scale was used to measure the psychological aspects of the participant returning to sport and the Shortened Profile of Mood States (S-POMS) was used to measure mood states of those who had undergone ACLR. ${ }^{15,17}$ The S-POMS consists of 37 topics for six different emotion categories which include: tension/anxiety, depression/dejection, anger/hostility, fatigue/inertia, vigor/activity and concussion/bewilderment. ${ }^{17}$ The Pain Catastrophizing Scale (a 13-item scale) was also used to ask participants questions about their thoughts and feelings in regards to the pain after ACLR. ${ }^{18}$ An example of a question that would be asked on the scale is "when I'm in pain, I worry all the time about whether the pain will end." 18

Based on the Tripp et al. study, confidence was assessed to determine how ready an athlete was to RTS. ${ }^{16}$ To measure confidence, the Sport Self-Confidence Inventory, which consisted of 13 different topic areas, was used to assess the confidence participants had about participation in sports. ${ }^{19}$ Those that scored a 1 were said to have low confidence and those that scored a 9 had high confidence. ${ }^{19}$ The results of this study showed that those who had a high fear of re-injury and negative mood states after ACLR were more likely to have low confidence in RTS. This correlation was evident in those that reported a higher fear of sustaining a second ACL injury and were more likely to see lower levels of RTS in their respective sport(s). ${ }^{16}$

\section{Psychological Factors Affecting Return to Sport}

Nwachukwu et al. (2019) conducted a study in which they researched the different factors that affected RTS. ${ }^{20}$ They found factors that affected RTS both at the pre-operative and post-operative level for athletes, which seemed to vary. At the pre-operative level, they found that motivation of RTS, importance of RTS, and the possibility of RTS played a large role in the psychological readiness for an athlete to return to their sport. At the post-operative level, they found other variables that played a factor in RTS. These variables were the motivation they felt during rehabilitation such as physical therapy, self-esteem throughout the recovery process, their locus of control (in terms of their health) and also varying states of mood.20

Similarly, a study conducted by Ardern et al. (2013) found that positive or negative mental states may influence athletes' decisions in RTS. ${ }^{21}$ If an athlete has a positive psychological response to surgery and post-operative rehabilitation, using crutches or physical therapy, they are more likely to RTS after a 12-month period than those who have a negative psychological response to RTS. ${ }^{21}$ While a patient is undergoing rehabilitation, it is essential to facilitate a positive psychological response to ensure a quicker RTS.

There are instances in which an athlete may sustain a second ACL injury and experience similar or heightened psychological reactions or emotions from the first injury. Webster et al. (2018) conducted a study in which they focused their research on psychological readiness when an athlete has sustained a second ACL injury after undergoing ACLR for their first injury.22 Psychological readiness was determined by the Anterior Cruciate Ligament Return to Sport After Injury Scale (ACL-RSI). ${ }^{23}$ This scale measures an athlete's emotion, confidence, and risk appraisal. For independent measures, there were five variables that were measured: surgical timing (i.e., the timing in between when an athlete sustained their injury to the time they underwent surgery), pre-injury sports participation (i.e., how active the athlete was in their sport before the injury occurred), knee laxity (i.e., how much an athlete is able to bend their knee), limb symmetry index (i.e., how similar each athlete's knees are) and subjective knee symptoms and functions, reported by the patient. ${ }^{22}$

The results of Webster et al. (2018) suggested that young males athletes had a decreased time between injury and surgery, had a higher level of pre-injury sports participation, a higher limb symmetry, higher knee scores, and reported a higher psychological readiness for RTS after sustaining a second ACL injury, when compared to young female athletes, suggesting sex differences. ${ }^{22}$ These higher subjective knee scores combined with a confidence to ensure proper rehabilitative outcomes is also correlated with a higher psychological readiness to RTS. These sex differences have also been demonstrated in another study by Ardern and colleagues about men that have a higher psychological readiness to RTS. ${ }^{6}$ They also suggested that male athletes are also more likely to return to their previous level of competition before their injury occurred compared to female athletes. ${ }^{6}$

While there are many studies that have been previously published that focus on why an athlete may be experiencing the emotions post-injury, there may be another explanation about this "fear" that athletes experience when they RTS. Walker et al. (2010) conducted a study in which they focused on the topic of "re-injury anxiety". ${ }^{24}$ This concept centers around why fear may not be the proper term to use for what an athlete is experiencing when they RTS. Walker and colleagues stated that fear is more of a biological response, but anxiety is more of the anticipatory feeling that an athlete may experience when they are contemplating the timeframe in which they should RTS. ${ }^{24}$ This could also correlate with psychological readiness; if an athlete reports more of the "re-injury anxiety", then they may exhibit lower levels of psychological readiness to RTS. 
Further research has demonstrated there are more psychological factors affecting readiness to RTS, including self-efficacy, stress, and social and contextual factors. A study conducted by Everhart et al. (2015) focused on three psychological domains that affect RTS: fear avoidance, self-efficacy, and stress and health. ${ }^{25}$ To measure fear, the Fear Avoidance Model, was used in which they found those who had a negative outlook response to the injury also had a negative emotional response to their ACL injury. ${ }^{26}$ To measure self-efficacy, the Theory of Self Efficacy was used. ${ }^{27}$ Using this measurement, it was found that having a patient set goals and portray positive self-talk performed better in their rehabilitative measures and thus had a higher level of RTS. ${ }^{25}$ Stress and health were measured by the Stress, Health and Buffering Hypothesis. ${ }^{28}$ It was found that individuals with higher stress combined with social support had better exercise completion both on their own and in physical therapy. However, to achieve these positive results, athletes must be willing to push past the fear of sustaining another injury to their ACL and be willing to return to their sport at the same level of functioning pre-injury. ${ }^{21}$

A second article by Ardern et al. (2015) focuses on the physical, social, and contextual factors that play into psychological readiness for an athlete to RTS. ${ }^{29}$ Specifically, sociodemographic factors such as age, sex, ethnicity, and socioeconomic status can play a larger factor in RTS. ${ }^{29}$ Ultimately, this could hinder an athlete's rehabilitative outcome and may lead to a decreased level of psychological readiness. Finally, another limitation may stem from the overall performance of an athlete's knee, focusing specifically on motor control and balance.

\section{Concussions}

Concussions are injuries that occur inside the brain hence researchers cannot see them properly to fully diagnose and understand them. ${ }^{30}$ There is a plethora of symptoms that can be seen and used to gauge a greater understanding of what occurs inside of the brain after it has been jolted by an outside force. Concussions can have physical symptoms, which can stem from headaches to feelings of dizziness, cognitive problems (e.g., difficulty with memory, the inability to concentrate, etc.), trouble sleeping, and emotional disruptions (e.g., irritability and anxiety). ${ }^{30}$ These symptoms will be analyzed in further detail in the following sections.

\section{Recovery Patterns After Sustaining a Concussion}

Recovery patterns after an athlete sustains a concussion can often be difficult since there are a variety of symptoms an athlete can possess. These symptoms are also based on the athlete's self-report, which may not be reliable and include individual differences since self-reports tend to be biased as people like to present themselves in a more favorable demeanor. A study conducted by Teel et al. (2017) focused on some of the symptoms that may occur after sustaining a concussion. ${ }^{31}$ They determined that an athlete that had loss of consciousness (LOC) may experience amnesia, which may occur in two types: post-traumatic amnesia and retrograde amnesia. Athletes may experience post-traumatic amnesia in which they would not be able to remember anything after sustaining the concussion. Other times, they may experience retrograde amnesia, where athletes would not be able to remember anything prior to the concussion occurring. ${ }^{31}$ This information was used in augmentation to three additional measures used to assess concussion symptoms, psychological assessments, and balance which are detailed below.

The Graded Symptom Checklist (GSC) was used to determine symptoms, ranging on a scale from 0-6 with 0 meaning no symptoms and 6 being the most severe. ${ }^{32}$ This measure recorded four different types of symptoms: somatic (early and evolving onset), cognitive, and neurobehavioral symptoms. Early onset somatic symptoms could be dizziness, headaches, nausea, and vomiting. Evolving onset somatic symptoms could include drowsiness and fatigue. Cognitive symptoms could be having a hard time concentrating and remembering, and neurobehavioral symptoms could range from difficulty sleeping to sadness. ${ }^{31}$

The Standardized Assessment of Concussion (SAC) was used to measure concentration, orientation to the room and objects, immediate and delayed memory, sensation, strength, and coordination. ${ }^{33}$ This was measured in a range of $0-30$, with a lower score indicating that the athlete possessed worse symptoms. The Balance Error Scoring System (BESS) was used to measure balance on each individual, as well as both legs. ${ }^{34}$ This was measured with a range of scores from $0-60$, with the higher the score denoting worse balance.

These assessments showed that those who had previously suffered from LOC and suffered from 0-30 minutes of amnesia were more likely to have worse symptoms in any category. Those who had over thirty minutes of amnesia had worse balance while athletes who sustained more than two concussions in their athletic history also exhibited worse balance overall. ${ }^{31}$

Anxiety and Social Support After Sustaining a Concussion

Psychological traits and symptoms can impose as much of a hindrance on an athlete after a concussion as if they were to sustain an injury that would require surgery. A study conducted by Covassin et al. (2014) focused on anxiety and the amount of social support an athlete receives from anyone they may interact with after they have sustained their concussion. ${ }^{35}$ This was also compared with the social support that an athlete may experience if they have undergone an orthopedic surgery, such as an ACLR. 
The State-Trait Anxiety Inventory (STAI) was used to determine how much anxiety an athlete experienced. ${ }^{36}$ For this, there were two types: state anxiety and trait anxiety. State anxiety is measured by how much an athlete experiences anxiety in the moment about different scenarios they may be presented with during rehabilitation and RTS. Trait anxiety measures how much anxiety an athlete feels in general about different scenarios. ${ }^{36}$ The 6 Item Social Support Questionnaire (ISSQ) was used to assess the amount of social support an athlete felt, which was broken into two parts. ${ }^{37}$ Athletes were first asked to provide information about the social support they received and were then asked to rate the overall satisfaction from this social support.

The results were quite similar when compared with athletes that had an orthopedic surgery. Athletes who had sustained a concussion received social support from family $(89 \%)$, friends $(78 \%)$, teammates $(65 \%)$, physical therapists $(48 \%)$, coaches $(47 \%)$, and doctors $(35 \%)$. Those who had undergone an orthopedic surgery were also relatively similar, with their highest amount of social support also coming from family and friends. Having positive social support after a concussion also allows for the athlete to reduce their stress. A positive perception of the social support they received also influenced the reduced levels of anxiety. ${ }^{35}$ It was also found that athletes after a concussion were more likely to display trait anxiety.

\section{Depressive Symptoms in Concussed Athletes}

Along with stress and anxiety an athlete may incur after sustaining a concussion, there is also the possibility for depressive symptoms to become prevalent. A study conducted by Roiger et al. (2015) showed the results of depression in patients that had received a concussion. ${ }^{38}$ They used the Center for Epidemiological Studies Depression Scale (CES-D) to assess depressive states, one week, one month and three months post-concussion. ${ }^{39}$ They found that after the timeframe of one week, athletes showed the most depressive symptoms. These symptoms decreased over time between the one week and one-month time frame. However, none of these levels posed these athletes to be at risk for a clinical diagnosis for depression. ${ }^{38}$

A study conducted by Guo et al. (2018) also found similar findings as Roiger and colleagues. ${ }^{40}$ This research compared depressive symptoms to those that had undergone orthopedic injuries and found that athletes that had sustained a concussion also showed higher rates of depressive symptoms. They also used the same measure, the CES-D, to assess the depressive symptoms in concussed athletes. ${ }^{40}$

\section{Post-Concussion Return to Play Expectations}

Similar to ACL injuries, there is also a certain timetable deemed both safe and suitable for an athlete to return to their respective sport. Since concussions are a closed head injury, it makes it more difficult to determine when an athlete should be cleared to play. A study conducted by Kelly and Erdal (2016) aimed to identify some characteristics, illustrated below, that may provide more insight to the timeframe in which athletes can RTS. ${ }^{41}$ The State-Trait Anxiety Inventory (STAI) was used to determine anxiety post-concussion. ${ }^{36}$ The Neurobehavioral Symptom Inventory (NSI) was used to measure traumatic brain injury (TBI) symptoms, as well as the Illness Perceptions Questionnaire-Revised (IPQ-R) to assess how the concussion affected the athlete's life.42-43 The results of this study illustrated that athletes with a history of concussions were more likely to exhibit more post-concussion symptoms. ${ }^{41}$ If an athlete also identified as being more athletic prior to their concussion, they also were seen to exhibit less days in between when they sustained the injury and when they decided to RTS. ${ }^{41}$ It was also found that amnesia, the type of concussion symptom, and LOC played a significant role in an athlete's decision to RTS. ${ }^{31}$

Concussions being a closed head injury are subject to many self-reported symptoms or instances where an athlete may say they are ready to return to their sport when they inherently may not be. Lower rates of fear of re-injury have been shown to be present in athletes, post-concussion due in part to self-report. ${ }^{40}$ Anxiety has also been shown to decrease over time because the injury may not be taken as seriously as an orthopedic injury, such as that of an ACL injury. ${ }^{40}$

\section{Summary of Results}

This review discovered both similarities and unique psychological hindrances for athletes suffering from ACL injuries or concussions when returning to sport. Table 2 below illustrates the psychological hindrances that are present in ACLs and concussions based on the information that has been discussed in the results section. While each respective sport contains hindrances specific to the injury, there is still some overlap. This is illustrated by the third column of the table which illustrates the shared psychological hindrances present in both injuries. 


\begin{tabular}{|c|c|c|}
\hline Injury & Psychological Hindrances & Shared Characteristics \\
\hline ACLs & $\begin{array}{ll}\text { - } & \text { Motivation to return to sport } \\
\text { - } & \text { Importance of return to sport } \\
\text { - } & \text { Possibility of return to sport } \\
\text { - } & \text { Emotion } \\
\text { - } & \text { Self-efficacy } \\
\text { - } & \text { Physical impairments } \\
\text { - } & \text { Quality of life } \\
\text { - } & \text { Severity of injury }\end{array}$ & $\begin{array}{ll}\text { - } & \text { Self-reported fear } \\
\text { - } & \text { Fear of re-injury } \\
\text { - } & \text { Self-esteem } \\
\text { - } & \text { Locus of control }\end{array}$ \\
\hline Concussions & $\begin{array}{ll}\text { - } & \text { Amnesia } \\
\text { - } & \text { Concentration } \\
\text { - } & \text { Coordination } \\
\text { - } & \text { Dizadaches } \\
\text { - } & \text { Depression } \\
\text { - } & \text { Pre-injury History } \\
\text { - } & \text { Cognitive Risks (CTE and Dementia) }\end{array}$ & $\begin{array}{ll}\text { - } & \text { Anxiety } \\
\text { - } & \text { Stress } \\
\text { - } & \text { Recovery patterns } \\
\text { - } & \text { Social support }\end{array}$ \\
\hline
\end{tabular}

Table 2. The shared common and different psychological hindrances that may be found in athletes after an ACL injury or concussion.

\section{DISCUSSION}

Based on the findings from this literature review, there are many psychological hindrances that can affect RTS after an athlete has sustained an ACL injury or a concussion. Though every athlete's experience is unique, level of fear and anxiety were shown to be the two strongest predictors in both injuries when deciding when to RTS.

According to Ardern et al. (2015), the severity of the injury which is perceived by the individual may affect their psychological readiness, especially in rehabilitative measures, such as physical therapy. ${ }^{29}$ If a patient feels that their injury is severe, they may not want to return on the specified timetable their doctor has advised them to follow or they may personally hinder themselves by not taking rehabilitation as seriously as they should, delaying their RTS.

Motivation also plays an active role in how prepared an athlete feels to RTS. This is exhibited throughout the recovery process from rehabilitation to RTS. ${ }^{20}$ The motivation to return can also be hindered by the severity of the injury mentioned above. If an athlete feels their injury is too severe, this may impede the return process and in turn decrease their motivation to RTS.

Though not the focus of this review, return to sport is a complex process that can be affected by not just psychological, but also physical and social impairments. The findings of this review support those reported previously by Ardern et al. (2015). ${ }^{29}$ Physical impairments may also accompany an athlete's mental impairments. Muscle strength, pain, knee stability, knee swelling, and knee movement can all play a big role in how much an athlete feels they are able to RTS. ${ }^{29}$ If an athlete has physical hindrances that inhibit them in their RTS, this will inherently influence their mental state and further inhibit them on their RTS. Figure 1 summarizes commonalties between this review and Ardern et al. (2015). Psychological factors that affect RTS following ACL injuries including physical impairments, such as muscle strength, pain, stability of the knee, swelling of the knee, and the overall movement of the knee. Social and contextual factors may differ between athletes, some being too optimistic or too pessimistic about the recovery outcomes. All these factors are intertwined with one another, as well as combined with others. Certain variables such as the cause and severity of the injury could play a large role in an athlete's psychological readiness to RTS. 


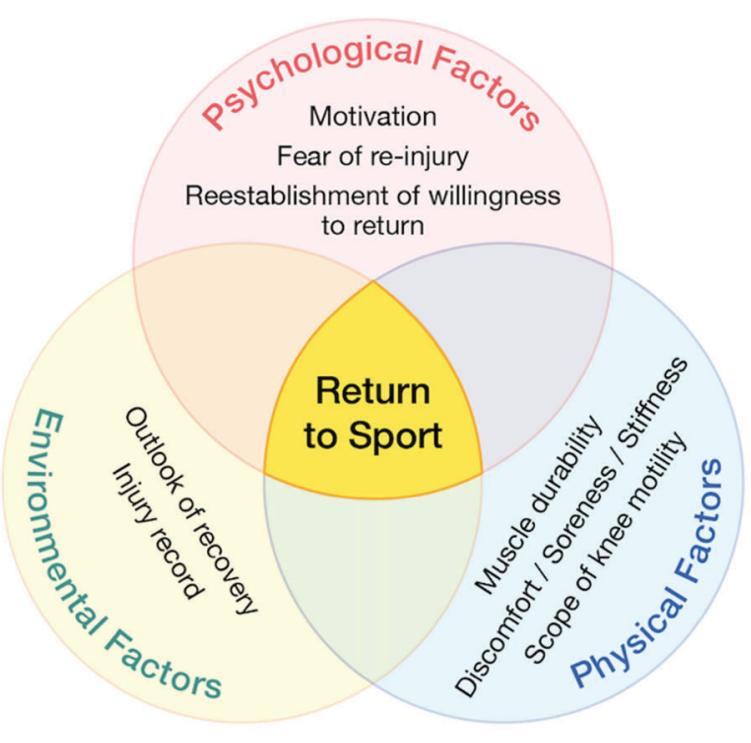

Figure 1. Biopsychosocial model of return to sport after an ACL injury. Adapted from Ardern, C. L., Kvist, J., \& Webster, K. E., Biopsychosocial model (2015).29

Throughout this literature review, the research has illustrated that there are many psychological hindrances that affect RTS after an athlete has sustained an ACL injury. Concussions also pose their own set of psychological hindrances when an athlete is considering returning to their sport.

Depression plays a substantial role in when an athlete can RTS. Depressive symptoms were shown to be higher in athletes who sustained a concussion compared to those that underwent orthopedic injuries. ${ }^{40}$ While these athletes show depressive symptoms, elevated from normal depressive levels, these levels are not a cause for concern for the athlete. Levels are not high enough for a clinical diagnosis and will return to their normal levels once the athlete returns to their sport. ${ }^{38}$ While depression can be a hindrance in RTS, it can be overcome with time.

Pre-injury history can also influence RTS after sustaining a concussion. If athletes had a history of prior concussions, they showed a higher likelihood of having post-concussion symptoms. ${ }^{41}$ These symptoms could include depressive symptoms as mentioned above. If an athlete has prior concussions, they also may experience anxiety that would hinder them even further in the return process.

Those that sustain an ACL injury were seen to have higher levels of fear that were associated with being four times more likely to show lower levels of activity. ${ }^{14}$ This is illustrated after the athlete has undergone ACLR and is in the process of RTS. Concussed athletes also had self-reported fear. If they self-reported symptoms such as that of LOC or amnesia, athletes were shown to have a lower time frame in which they returned to sport. ${ }^{31}$

Fear of re-injury is very common in athletes who have sustained an ACL injury. However, if an athlete was able to set goals and possessed positive self-talk, they were shown to have higher levels of RTS. ${ }^{25}$ In a similar manner, athletes that sustained a concussion and had lower self-reported fear, had a lower fear of re-injury. ${ }^{40}$ This could also factor into a concussion being an invisible injury since there may not be any physical symptoms seen in concussed athletes.

Anxiety and stress are both detriments to the return process after sustaining an ACL injury or concussion. For ACL injuries, even if athletes had a higher stress level, if they possessed a high level of social support, they possessed better physical therapy outcomes. These combined factors allowed for an overall lower stress level when deciding to RTS. However, an athlete would have to push past the fear of a second ACL injury to return to their previous level, meaning they would need to surpass their levels of stress. ${ }^{25}$

For concussions, high trait anxiety was shown to decrease and aid in an athlete's RTS. ${ }^{40}$ Similarly, to ACL injuries athletes that sustained concussions but had a higher level of social support were able to reduce their stress levels. Athletes that exhibited a positive perception of social support displayed an overall reduction level in anxiety. ${ }^{35}$ 


\section{CONCLUSION}

ACL injuries and concussions are some of the most prominent injuries in sports at any level. This literature review summarizes the psychological hindrances that affect RTS after sustaining an ACL injury or concussion and provides future directions that could be beneficial to the athletic community including coaches, parents, educational institutions, and the athletes themselves. In addition, this review could bring more awareness of the similar and unique psychological factors presented by ACL injuries and concussions inhibiting an athlete's return to sport. The summary list of potential psychological factors hindering athletes from returning to sport could allow the athletic community to be better equipped to provide the best type of assistance for the athletes to RTS in a safe and supportive manner. This literature review could also spark the interest of medical professionals to incorporate better rehabilitative practices into their work with athletes. In doing so, this will create interest in conducting new studies to see how athletes will respond to different types of rehabilitation during the process of returning after injury.

\section{ACKOWLEDGEMENTS}

The authors thank Audrey Bell- the medical illustrator in the Department of Foundational Medical Studies at OUWB- for illustrating the figure that is included in this manuscript.

\section{REFERENCES}

1. National Federation of State High School Associations. (2019). 2018-19 bigh school athletics participation survey. https:/ / www.nfhs.org/media/1020412/2018-19_participation_survey.pdf

2. National Collegiate Athletic Association. (2020). Student-athlete participation, 1981-82, 2018-19. NCAA® Sports Sponsorship and Participation Rates Report. https://ncaaorg.s3.amazonaws.com/research/sportpart/201819RES_Sports_SponsorshipParticipationRatesReport.pdf

3. Woods, R. A. (2017). Spotlight on statistics: sports and exercise. U.S. Bureau of Labor Statistics. https:// www.bls.gov/spotlight/2017/sports-and-exercise/pdf/sports-and-exercise.pdf

4. Kim, S., Bosque, J., Meehan, J. P., Jamali, A., \& Marder, R. (2011). Increase in outpatient knee arthroscopy in the United States: a comparison of National Surveys of Ambulatory Surgery, 1996 and 2006. Journal of Bone and Joint Surgery, 93 (11): 9941000. https://doi.org/10.2106/jbjs.i.01618

5. Ardern, C. L., Taylor, N. F., Feller, J. A., \& Webster, K. F. (2012). Return-to-sport outcomes at 2 to 7 years after anterior cruciate ligament reconstruction surgery. American Journal of Sports Medicine, 40:4148. bttps:// doi.org/ 10.1177/0363546511422999

6. Ardern, C. L., Taylor, N. F., Feller, J. A., \& Webster, K. F. (2014). Fifty-five percent return to competitive sport following anterior cruciate ligament reconstruction surgery; an updated systematic review and meta-analysis including aspects of physical functioning and contextual factors. British Journal of Sports Medicine, 48:1543-1552. bttps:/ / doi.org/ 10.1136/ bjsports-2013093398

7. Ardern, C. L. (2015). Anterior cruciate ligament reconstruction- not exactly a one-way ticket back to the preinjury level: a review of contextual factors affecting return to sport after surgery. Sports Health: a multidisciplinary approach, 7(3), 224-230. https:// doi.org/10.1177/1941738115578131

8. Centers for Disease Control and Prevention. (2016). Injury prevention and control: traumatic brain injury and concussion. https:// www.cdc.gov/traumaticbraininjury/get_the_facts.html

9. Waltzman, D., Womack, L.S., Thomas, K.E., Sarmiento, K. (2020). Trends in Emergency Department Visits for Contact Sports-Related Traumatic Brain Injuries Among Children - United States, 2001-2018. MMWR Morb Mortal Wkly Rep, 69, 870-874. http://dx.doi.org/10.15585/ mmwr.mm6927a4external icon

10. National Collegiate Athletic Association (2014). Mind, body and sport: understanding and supporting student-atblete mental wellness. https://www.naspa.org/images/uploads_events/Mind_Body_and_Sport.pdf.

11. Wiebe, D. J., Comstock, R. D., \& Nance, M. L. (2011). Concussion research: a public health priority. Injury Prevention, 17, 6970. bttps: / / doi.org/10.1136/ip.2010.031211

12. Kirschen, M. P., Tsou, A., Nelson, S. B., Russell, J. A., \& Larriviere, D. (2014). Ethics, law, and humanities committee, a joint committee of the American Academy of Neurology, American Neurological Association, and Child Neurology Society. Legal and ethical implications in the evaluation and management of sports-related concussions. Neurology, 83(4): 352-358. https:// doi.org/ 10.1212.wnl.0000000000000613

13. Goldman, K. D., \& Schmalz, K. J. (2004). The matrix method of literature reviews. Health Promotion Practice, 5(1), 5-7.

14. Paterno, M. V., Flynn, K., Thomas, S., \& Schmitt, L. C. (2018). Self-reported fear predicts functional performance and second ACL injury after ACL reconstruction and return to sport: A pilot study. Sports Health: A Multidisciplinary Approach, 10(3), 228-233. https:// doi.org/10.1177/1941738117745806

15. George, S. Z., Lentz, T. A., Zeppieri, G., Lee, D., \& Chmielewski, T. L. (2012). Analysis of shortened versions of the Tampa Scale for Kinesiophobia and Pain Catastrophizing Scale for patients after anterior cruciate ligament reconstruction. Clinical Journal of Pain, 28:73-80. https:// doi.org/10.1097/ajp.0b013e31822363f4 
16. Tripp, D. A., Stanish, W., Ebel-Lam, A., Brewer, B. W., \& Birchard, J. (2011). Fear of reinjury negative affect, and catastrophizing predicting return to sport in recreational athletes with anterior cruciate ligament injuries at 1-year postsurgery. Sport, Exercise, and Performance Psychology, 1(5), 38-48. https:// doi.org/10.1037/2157-3905.1.s.38

17. Shacham, S. (1983). A shortened version of the Profile of Mood States. Journal of Personality Assessment, 47: 305-306. bttps:// doi.org/ 10.1207/s15327752jpa4703_14

18. Sullivan, M. J., Bishop, S., \& Pivik, J. (1995). The Pain Catastrophizing Scale: development and validation. Psychological Assessment, 7:524-532. https://doi.org/10.1037/1040-3590.7.4.524

19. Vealey, R., Hayashi, S.W., Garner-Holman, M., \& Giacobbi, P. (1998) Sources of sport confidence: conceptualization and instrument development. Journal of Sport and Exercise Psychology, 20:54-80. https:// doi.org/10.1123/jsep.20.1.54

20. Nwachukwu, B. U., Adjei, J., Rauck, R. C., Chahla, J., Okoroha, K. R., Verma, N. N., Allen, A.A Williams, R. J. (2019). How much do psychological factors affect lack of return to play after anterior cruciate ligament reconstruction? A systematic review. Orthopedic Journal of Sports Medicine, 7(5), 1-7. https:/ / doi.org/10.1177/2325967119845313

21. Ardern, C. L., Taylor, N. F., Feller, J. A., Whitehead, T. S., \& Webster, K. E. (2013). Psychological responses matter in returning to preinjury level of sport after anterior cruciate ligament reconstruction surgery. The American Journal of Sports Medicine, 41(7), 1549-1558. https:/ / doi.org/10.1177/0363546513489284

22. Webster, K. E., Nagelli, C. V., Hewett, T. E., \& Feller, J. A. (2018). Factors associated with psychological readiness to return to sport after anterior cruciate ligament reconstruction surgery. The American Journal of Sports Medicine, 46(7), 1545-1550. https:// doi.org/10.1177/0363546518773757

23. Webster, K. E. \& Feller J. A. (2016). Exploring the high injury rate in younger patients undergoing anterior cruciate ligament reconstruction. American Journal of Sports Medicine, 11: 2827-2832. https://doi.org/10.1177/0363546516651845

24. Walker, N., Thatcher, J., \& Lavallee, D. (2010). A preliminary development of the Re-Injury Anxiety Inventory (RIAI). Physical Therapy Sport, 11:23-29. https:// doi.org/10.1016/j.ptsp.2009.09.003

25. Everhart, J. S., Best, T. M., \& Flanigan, D. C. (2015). Psychological predictors of anterior cruciate ligament reconstruction outcomes: a systematic review. Knee Surgery Sports Traumatology and Arthroscopy, 23:752-762. https://doi.org/10.1007/s00167-0132699-1

26. Lethem, J, Slade, D.G., Troep, J.D.G., \& Bentley, G. (1983) Outline of a fear-avoidance model of exaggerated pain perception. Behavior Research and Therapy, 21(4): 401-408. https:/ / doi.org/ 10.1016/0005-7967(83)90009-8

27. Bandura, A. (1977). Self-efficacy: toward a unifying theory of behavioral change. Psychology Review, 84(2):191. https:// doi.org/10.1037/0033-295x.84.2.191

28. Cohen, S. \& Wills, T. A. (1985). Stress, social support, and the buffering hypothesis. Psychological Bulletin, $98(2): 310-357$. bttps:// doi.org/ 10.1037/0033-2909.98.2.310

29. Ardern, C. L., Kvist, J., \& Webster, K. E. (2015). Psychological aspects of anterior cruciate ligament injuries. Operative Techniques in Sports Medicine, 24(1), 77-83. https:/ / doi.org/10.1053/j.otsm.2015.09.006

30. Kontos, A. P., Elbin, R., Schatz, P., Covassin, T., Henry, L., Pardini, J., \& Collins M.W. (2012). A revised factor structure for the post-concussion symptom scale: baseline and post-concussion factors. The American Journal of Sports Medicine; 40(10): 23752384. bttps:// doi.org/10.1177/0363546512455400

31. Teel, E. F., Marshall, S. W., Shankar, V., McCrea, M., \& Guskiewicz, K. M. (2017). Predicting Recovery Patterns After SportRelated Concussion. Journal of Athletic Training, 52(3): 288-298. https:/ / doi.org/ 10.4085.1062-6050-52.1.12

32. Iverson, G. (2007). Predicting slow recovery from sport-related concussion: the new simple-complex distinction. Clinical Journal of Sports Medicine, 17(1):31-37.

33. Slobounov, S., Slobounov, E., Sebastianelli, W., Cao, C., \& Newell, K. (2007). Differential rate of recovery in athletes after first and second concussion episodes. Neurosurgery, 61(2): 169-173. https:// doi.org/10.1227/01.neu.0000280001.03578.ff

34. Covassin, T., Stearne, D., \& Elbin, R. (2008). Concussion history and postconcussion neurocognitive performance and symptoms in collegiate athletes. Journal of Athletic Training, 43(2):119-124. bttps:/ / doi.org/ 10.4085/1062-6050-43.2.119

35. Covassin, T., Crutcher, B., Bleecker, A., Heiden, E. O., Dailey, A., \& Yang, J. (2014). Postinjury anxiety and social support among collegiate athletes: a comparison between orthopedic injuries and concussions. Journal of Athletic Training; 49(4): 462468. https:/ / doi.org/ 10.4085/1062-6059-49.2.03

36. Spielberger, C. D., Gorsuch, R. L., Lushene, R., Vagg, P. R. \& Jacobs, G. A. (1983). Manual for the state trait anxiety. Consulting Psychologists Press.

37. Sarason, I., Sarason, B., Shearin, E., \& Pierce, G. (1987). A brief measure of social support: practical and theoretical implications. Journal of Social and Personal Relationships, 4(4):497-510. https:/ / doi.org/ 10.1177/0265407587044007

38. Roiger, T., Weidauer, L. \& Kern, B. (2015). A longitudinal pilot study of depressive symptoms in concussed and injured/nonconcussed national collegiate athletic association division 1 student-athletes. Journal of Athletic Training, 50(3): 256261. https:// doi.org/10.4085/1062-6050-49.3.83

39. Radloff, L. S. (1997). The CES-D scale- a self-report depression scale for research in the general population. Applied Psychological Measurement; 1:385-401. https:/ / doi.org/10.1177/014662167700100306 
40. Guo, J., Yang, J., Yi, H., Singichetti, B., Starvinos, D., \& Peek-Asa, C. (2018). Differences in postinjury psychological symptoms between collegiate athletes with concussions and orthopedic injuries. Clinical Journal of Sports Medicine. Advance online publication. https:// doi.org/10.1097/JSM.0000000000000621

41. Kelly, K., \& Erdal K. (2016). Diagnostic terminology, athlete status, and history of concussions affect return to play expectations and anticipated symptoms following mild traumatic brain injury. Journal of Clinical and Experimental Neuropsychology, 39(6). 587-595. https:/ / doi.org/10.1080/13803395.2016.1250870

42. Cicerone, K. D., \& Kalmar, K. (1995). Persistent post-concussion syndrome: The structure of subjective complaints after mild traumatic brain injury. Journal of Head Trauma Rehabilitation, 10, 1-17. bttps:// doi.org/10.1097/00001199-199506000-00002

43. Moss-Morris, R., Weinman, J., Petrie, K., Horne, R., Cameron, L., \& Buick, D. (2002). The revised illness perception questionnaire (IPQ-R). Psychology and Health, 17:1-16. https:/ / doi.org/ 10.1080/08870440290001494

\begin{abstract}
ABOUT STUDENT AUTHOR
Ashley Sweeney graduated from the Oakland University Honors College in the Spring of 2020. During her undergraduate career, her major was Psychology and as a requirement to graduate with honors, she completed a narrative literature review. This review was completed alongside the help of mentors Stephanie M. Swanberg and Dr. Suzan Kamel-ElSayed. This literature review is an adapted version from her Honors College thesis which is showcased in the archives at the Kresge Library at Oakland University.

She is currently furthering her education at Oakland University, pursuing her Master's in Clinical Mental Health Counseling. She is also working as a Graduate Assistant in the Office of Undergraduate Admissions on campus, where she was previously a student ambassador for three years. After graduation, she has plans to work in the business/industry setting or opening her own private practice where she grew up in the Thumb of Michigan.
\end{abstract}

\title{
PRESS SUMMARY
}

This narrative review aims to determine the possible psychological hindrances present when an athlete is planning on returning to sport after injury to an anterior cruciate ligament (ACL) or after sustaining a concussion. Shared psychological characteristics for returning to sport following either an ACL injury or concussion included fear, self-esteem, control, anxiety, stress, recovery, and social support. Discovering the common and unique psychological barriers which may affect the injured athletes from returning to sport can help educate athletes' families, coaches, and healthcare professionals, as well as promote discussions for the future to help athletes feel more secure in their return to their respective sport. This information can not only bring awareness to the fields of psychology, exercise science and medicine, but also further exploration into prevention of these injuries. 